\title{
LIFESTYLE FACTORS INFLUENCE IN THE FREQUENCY IN BUCCAL MICRONUCLEUS
}

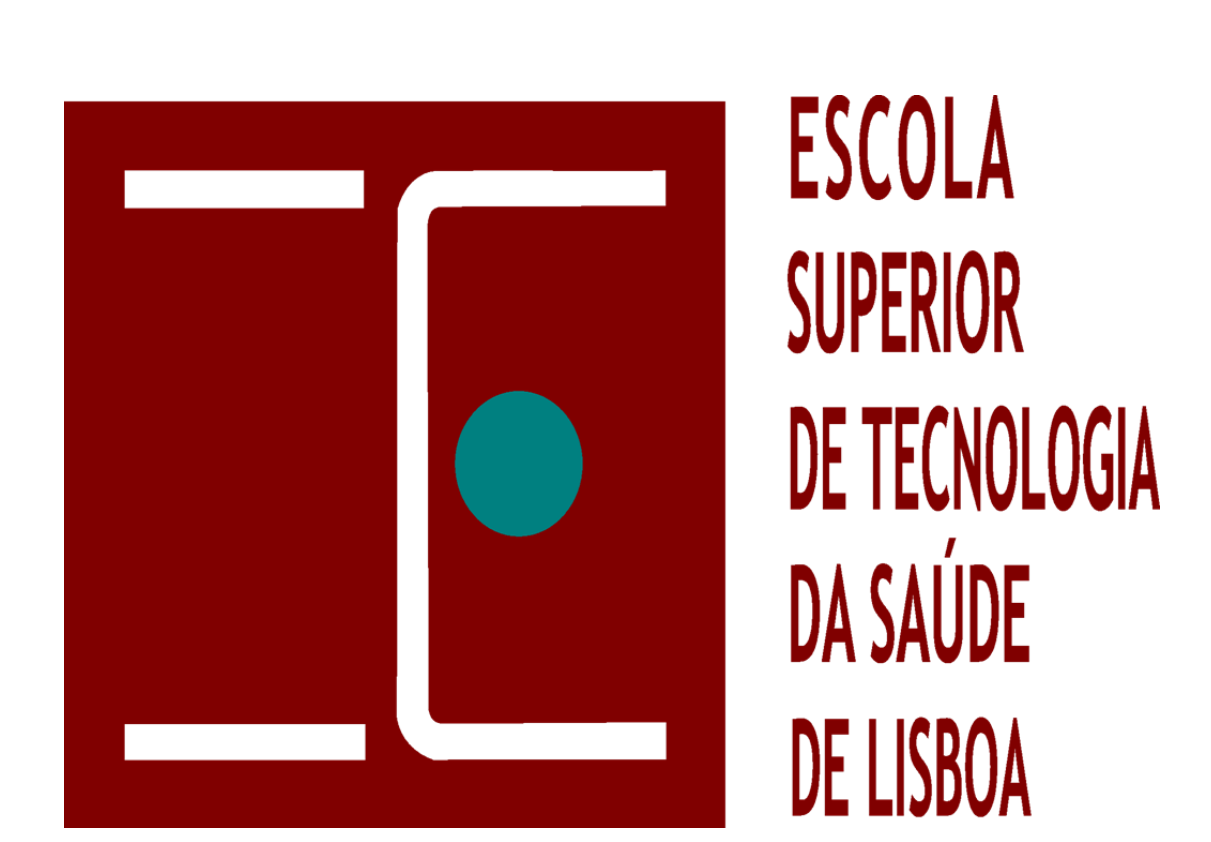

ISCOLA

DETECHOLOOLA

DASAUDE

DELLSBOA

\section{LADEIRA $1,2 \quad$ MC GOMES $3 \quad$ M BRITO 1}

1 -Higher School of Health Technologies of Lisbon, Polytechnic Institute of Lisbon

2 - CIESP National School of Public Health, New University of Lisbon; 3 - Faculty of Sciences, University of Lisbon

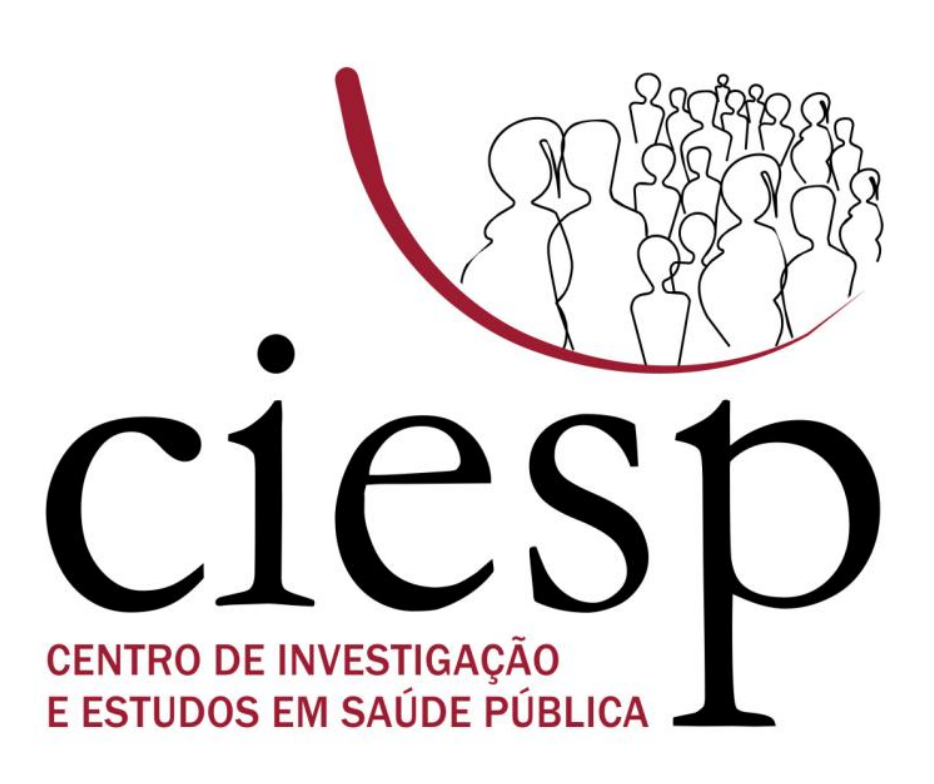

\section{INTRODUCTION}

Genomic damage is probably the most important fundamental cause of development and degenerative disease. It is also well established that genomic damage is produced by environmental exposure to genotoxins, medical procedures (e.g. radiation and chemicals), micronutrient deficiency (e.g. folate), lifestyle factors (e.g. alcohol, smoking, drugs and stress), and genetic factors such as inherited defects in DNA metabolism and/or repair. Tobacco smoke has been associated to a higher risk of development of cancer, especially in the oral cavity, larynx and lungs, as these are places of direct contact with many carcinogenic tobacco's compounds. Alcohol is definitely a recognized agent that influence cells in a genotoxic form, been citied as a strong agent with potential in the development of carcinogenic lesions. Epidemiological evidence points to a strong synergistic effect between cigarette smoking and alcohol consumption in the induction of cancers in the oral cavity. Approximately $90 \%$ of human cancers originate from epithelial cells. Therefore, it could be argued that oral epithelial cells represent a preferred target site for early genotoxic events induced by carcinogenic agents entering the body via inhalation and ingestion. The $M N$ assay in buccal cells was also used to study cancerous and precancerous lesions and to monitor

the effects of a number of chemopreventive agents.

\section{AIM OF THE STUDY \\ Determine the influence of lifestyle factors such as alcohol \\ consumption and smoking habits by measuring the frequency \\ of micronucleus in buccal mucosa cells}

\section{METHODOLOGY}

The study was carried out in Portugal in a sample 85 subjects without any occupational exposure and was asked about their smoking and drinking habits. The evaluation of genotoxic effects was conducted by applying $\mathrm{MN}$ test in exfoliated cells from buccal mucosa. Buccal cells were removed by endobrush and stained with Feulgen technique without counterstain.

\section{RESULTS}
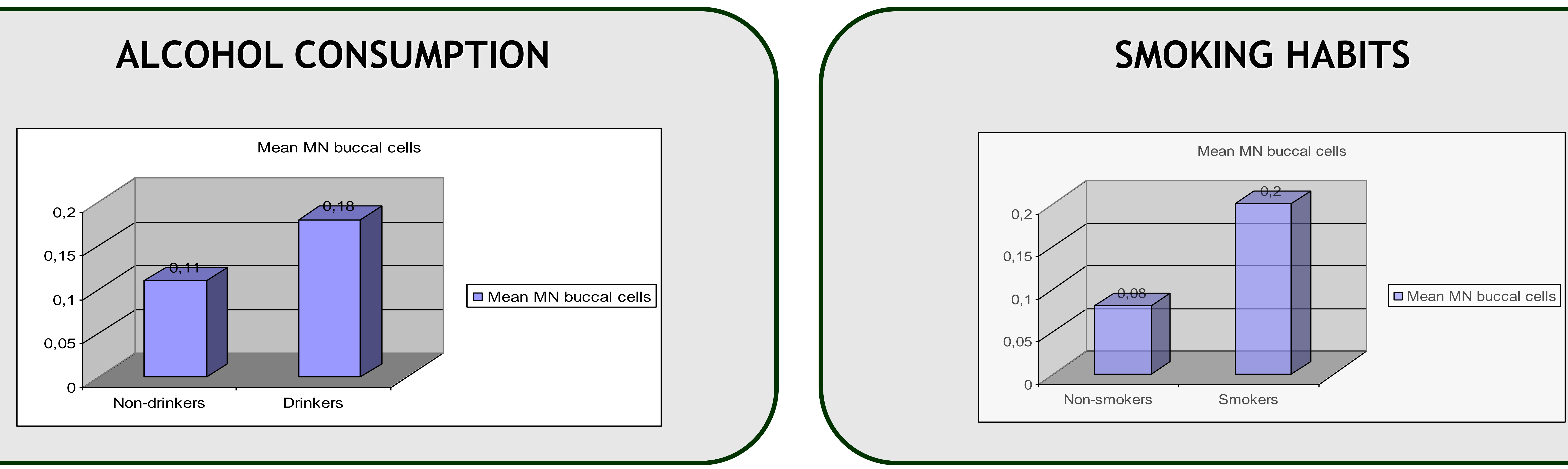

Subjects in study presented higher means of $M N$ in drinkers $(0.18 \pm 0.068)$ and in smokers $(0.2 \pm 0.074)$ in comparison with non-drinkers $(0.11 \pm 0.105)$ and non-smokers $(0.08 \pm 0.08)$ without statistical significance (Mann-Whitney test, $p>0.05)$. The analysis of the interaction between the alcohol consumption and smoking habits showed statistical signification $(p=0.043)$ with a stronger effect from tobacco smoke than alcohol consumption.

\section{CONCLUSIONS}

Epidemiological evidence points to a strong effect between cigarette smoking and alcohol consumption in the induction of cancers in the oral cavity. The interaction between alcohol consumption and smoking habits for the mean frequency of MN in buccal cells showed that subjects that do not smoke and do not drink tend to have lower frequencies than those who drink and smoke and in this interaction tobacco has a preponderant effect than alcohol. 